\title{
HPGe and Scintillation Detectors Comparisons on Waste Drums Radioactivity Measurement
}

\author{
Chin-Hsien Yeh, Wun-Jhih Huang, Ming-Chen Yuan, Hsiu-Wei Lee \\ Health Physics Division, Institute of Nuclear Energy Research, Taiwan \\ Email: chyeh@iner.gov.tw
}

Received 6 April 2016; accepted 8 August 2016; published 15 August 2016

\begin{abstract}
Two measurement systems, one being comprised of three HPGe detectors and the other being a $4 \pi$ measurement system of the assembly of 10 sets of scintillation detectors, were compared for their measurement performance in operations of radioactive waste drum radioactivity measurement and clearance and release operation of decommissioning. The system features of the former were high costs, capable of identifying radionuclides, a measurement time of about 1000 sec. The system features of the latter were high sensibility, capable of identifying hotspots, a measurement time of about 100 sec. Various comparisons were made for the differences of the two systems on reference drums, whole-drum homogeneous and non-homogeneous metal drums and non-metal drums, whole-drums of different filling rates. The aim was to compare the differences of the two measurement systems in measuring radioactivity of critical radionuclides of ${ }^{137} \mathrm{Cs}$, ${ }^{54} \mathrm{Mn}$ and ${ }^{60} \mathrm{Co}$.
\end{abstract}

\section{Keywords}

HPGe Detector, Scintillation Detector, Clearance

\section{Introduction}

For nuclear facilities decommissioning, HPGe detectors and highly sensible scintillation detectors which are capable of identifying energies and usually placed inside lead shields are used to measure the very low radioactivity (IAEA $\leq 0.1 \mathrm{~Bq} / \mathrm{g}$ ) of radioactive waste for clearance operations. The Institute of Nuclear Energy Research (INER) established two gamma radioactivity measurement systems which were respectively comprised of three

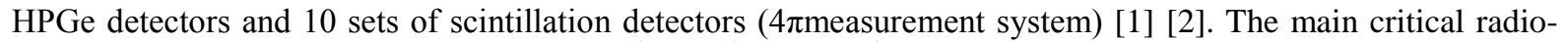
nuclides measured by the two systems are ${ }^{137} \mathrm{Cs}$, ${ }^{54} \mathrm{Mn}$ and ${ }^{60} \mathrm{Co}$. These two systems passed comparison programs on radioactive waste radioactivity measurements organized in Taiwan in 2009 and 2015 [3] [4]. The aim of this article is to discuss the difference of radioactivity analyses in various scenarios containing reference drums with homogeneous radioactivity distribution, waste drums with radioactivity similar to non-metal drums with homogeneous radioactivity distribution and metal drums with non-homogeneous radioactivity distribution, different filling ratios of whole-drum materials by using these two measurement systems. 


\section{Materials and Methods}

Two measurement systems, one being comprised of three HPGe detectors (Canberra Q2) and the other being a $4 \pi$ measurement system of the assembly of 10 sets of scintillation detectors (INER SWAM2) are illustrated as Figure 1. These two measurement systems were put to use under the assumption of using drums of homogeneous distribution, simulation of point radioactive source theory calculation and establishment of multiple-density reference drums to come out with counting efficiencies as given in Figure 2. The HPGe detectors measurement system and the scintillation detectors measurement system had respective standard combined uncertainties of $9 \%$ and $7 \%$. For the uncertainty evaluation of radioactivity measurement, decommissioning wastes were measured following the guideline from ISO. The performance differences of both measurement systems were listed in Table 1.

In this article, the concerned critical radionuclides were ${ }^{137} \mathrm{Cs},{ }^{60} \mathrm{Co}$ and ${ }^{54} \mathrm{Mn}$. These sources used were traceable to the national radiation standards with a standard uncertainty of less than $1 \%$. These critical radionuclides were used to make $40 \mathrm{~cm}$ diameter large-area source slice and1.5 cm diameter $60 \mathrm{~cm}$ long rod-shaped liquid

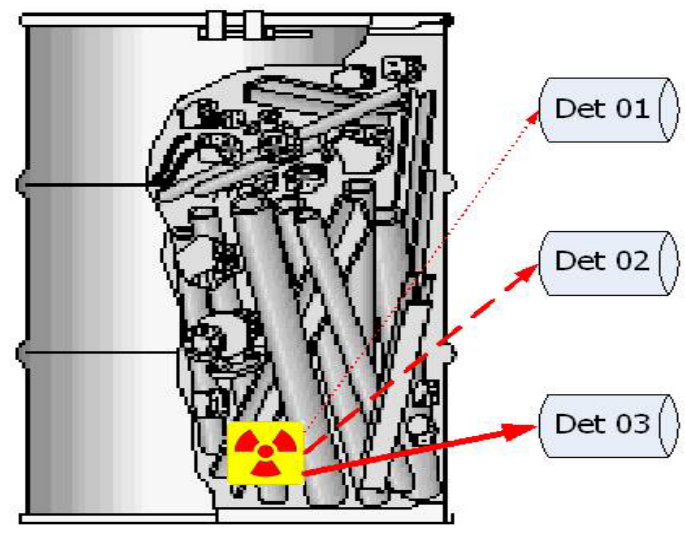

(a)

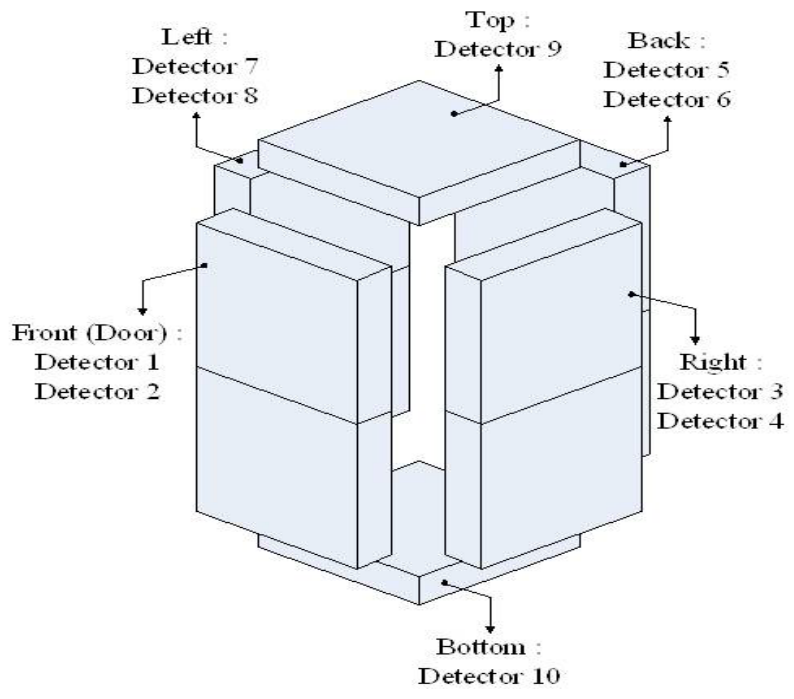

(b)

Figure 1. Measurement system of (a) three HPGe detectors and (b) $4 \pi$ scintillation detectors.

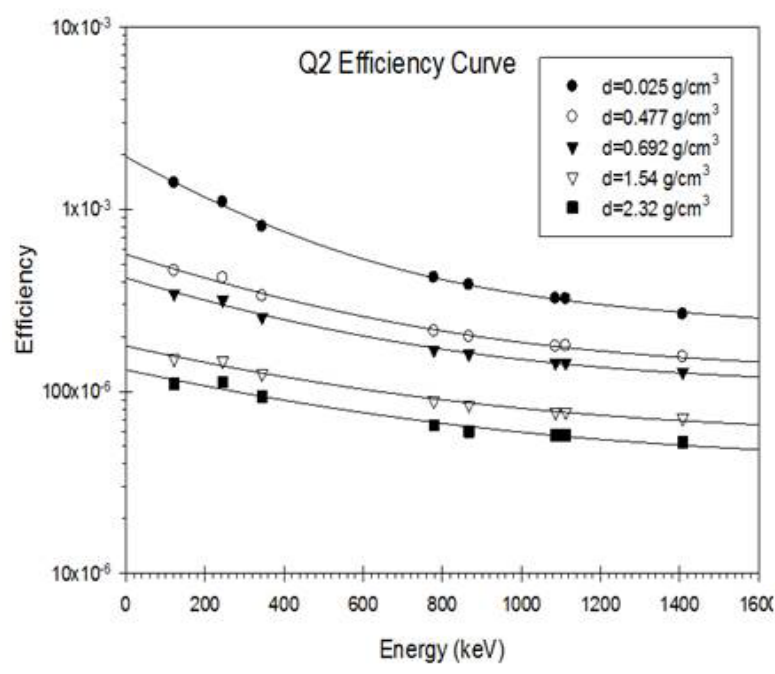

(a)

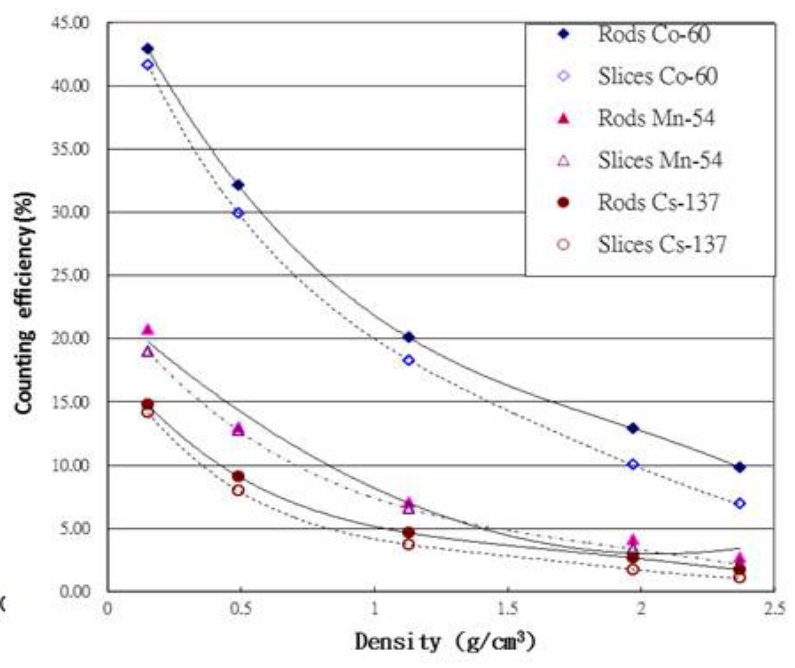

(b)

Figure 2. Efficiency of (a) three HPGe detectors and (b) $4 \pi$ scintillation detectors. 
Table 1. Characteristic of test drums for activity measurement.

\begin{tabular}{cccc}
\hline Matrix & Density $\left(\mathrm{g} / \mathrm{cm}^{3}\right)$ & Totalactives $(\mathrm{Bq})$ & Source distr. \\
\hline Water & 1.0 & $\sim 10 \mathrm{E} 3$ & uniform \\
Concrete & 1.9 & $\sim 10 \mathrm{E} 3$ & near uniform \\
Carbon & 1.0 & $\sim 10 \mathrm{E} 7$ & near uniform \\
Plastic & 1.1 & $\sim 10 \mathrm{E} 5$ & near uniform \\
Resin & 0.9 & $\sim 10 \mathrm{E} 5$ & near uniform \\
Concrete & $1.8-2.1$ & $\sim 10 \mathrm{E} 5$ & near uniform \\
Aluminium plate & $0.4-0.9$ & $\sim 10 \mathrm{E} 2$ & non uniform \\
Iron plate & $0.7-0.9$ & $\sim 10 \mathrm{E} 5$ & non uniform \\
Iron tube & $0.5-0.9$ & $\sim 10 \mathrm{E} 5$ & non uniform \\
\hline
\end{tabular}

source with homogeneous distribution. The radioactivities of the source slice and source rod were about $30 \mathrm{kBq}$ and the uncertainties were less than $1.5 \%(\mathrm{k}=2)$. For simulations of decommission wastes, test drums were made for various energies, matrix, densities, radioactivities and source distribution. Furthermore, single and mixed source containing ${ }^{137} \mathrm{Cs},{ }^{60} \mathrm{Co}$ and ${ }^{54} \mathrm{Mn}$ of water solution test drum and 16 source rods of concrete test drum were constructed with a homogeneous radioactivity distribution. Five metal test drums were made for different radiation hotspots positions on the upper, middle and lower horizontal levels of the iron plate of the drum, on the vertical center and on the tilting side with non-homogeneous radioactivity distribution. Three kinds of non-metal drums of different materials (resin, plastics, carbon) with homogeneous radioactivity distribution, 20 drums of aluminum plate with non-homogeneous radioactivity distribution, 16 drums of concrete with homogeneous radioactivity distribution and four drums with different filling ratios of plastic matrix were constructed. The homogeneity of radioactivity distribution was the ratio of the maximum cps from the individual scintillation detector to the average cps of all the scintillation detectors. The homogeneity of the water solution of the 10 detectors was lower than 1.5 .

\section{Result and Discussions}

Five simulations of 55 gallon drums with source distribution under different geometrical conditions were performed to compare the measurement results of these two measurement systems for the radioactivities of critical radionuclides of ${ }^{137} \mathrm{Cs},{ }^{54} \mathrm{Mn}$ and ${ }^{60} \mathrm{Co}$ as the following:

\section{Reference drum}

The reference drums used were traceable to the national radiation standards. Two types of reference drums containing water solution were constructed, one being made with a single radionuclide, the other being made with mixed radionuclides of ${ }^{137} \mathrm{Cs}$, ${ }^{54} \mathrm{Mn}$ and ${ }^{60} \mathrm{Co}$. The measurement results of the two measurement systems are given in the Table 2 . The maximum difference among the reference drums using single radionuclides and mixed radionuclides were $19 \%$ and $20 \%$, respectively.

\section{Hot-spot test}

The measurement results of the metal drum of non-homogeneous radioactivity distribution are given in the Figure 3 when the hot-spot lies in the upper, middle and lower levels of the horizontal axial or lies in the center or tilting part of the vertical axial of the whole drum. It showed that the radioactivity differences of the five hotspot positions of the scintillation detectors were larger than those of the HPGe detectors. The $4 \pi$ measurement system can identify the locations of the hotspots. However, the total radioactivity measurement of this system is obtained by adding up all the radioactivity results of every detector. It lacks of the weighting factors of individual detector for radioactivity corrections. In addition, both systems have their largest difference in the measurement results as the hotspots lying in the vertical axial center in the drums with non-homogenous distribution. Since the hotspots of ${ }^{137} \mathrm{Cs}$ and ${ }^{60} \mathrm{Co}$ are farthest away from the detectors, the self-absorption effect will also be the maximum. 
$\square$ Cs-137:Q2 - Cs-137:SAWM2 $\triangle$ C0-60:Q2 $\bullet$ Co-60:SAWM2

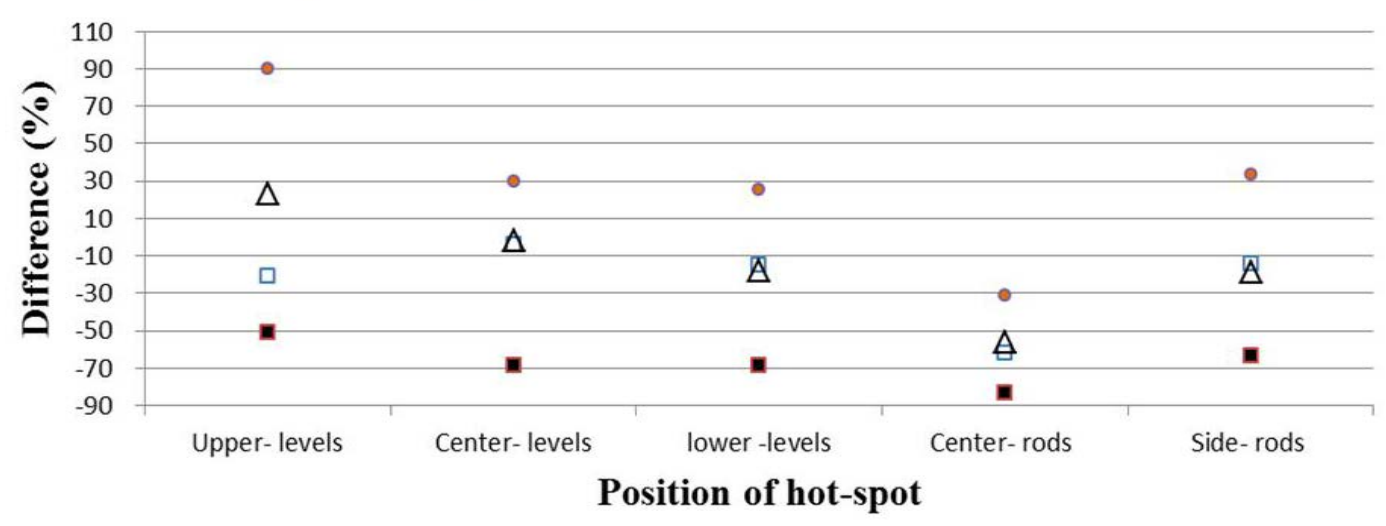

Figure 3. Comparison radioactivity of hot spots at different position of whole drum.

Table 2. Comparison activities of reference material drum..

\begin{tabular}{cccc}
\hline Nuclide & Activity $(\mathrm{Bq})$ & \multicolumn{2}{c}{ Difference (\%) } \\
\cline { 3 - 4 } & & Q2 & SWAM2 \\
\hline${ }^{137} \mathrm{Cs}$ & 4000 & 1.2 & -4.8 \\
${ }^{54} \mathrm{Mn}$ & 3660 & 16.0 & 19.2 \\
${ }^{60} \mathrm{Co}$ & 3957 & 5.0 & 18.8 \\
${ }^{\mathrm{Mix}-{ }^{137} \mathrm{Cs}}$ & 2000 & -20.0 & 9.4 \\
Mix- $^{54} \mathrm{Mn}$ & 1830 & 11.8 & 17.6 \\
Mix- ${ }^{60} \mathrm{Co}$ & 1980 & 11.2 & \\
\hline
\end{tabular}

\section{Non-metal drums of homogeneous distribution}

For the non-metal drums of homogeneous radioactivity distribution made of plastics, concrete, resin and carbon whose radioactivity in carbon was about 10E7, the measurement results of the two systems are given in Figure 4. When compared with the measurement average values obtained by the HPGe detectors for the fournon-metal drums with homogeneous radioactivity distribution, the differences of these two measurement systems are all less than $12 \%$. One thing noteworthy is that the differences obtained by the HPGe detectors for high radioactivity carbon in ${ }^{60} \mathrm{Co}$ were about $33 \%$ and the differences obtained by the scintillation detectors for concrete radionuclides were about $26 \%$ in ${ }^{137} \mathrm{Cs}$.In addition, based on the measurement of HPGe system, the comparison of measurement results of ${ }^{137} \mathrm{Cs}$ between two systems was given in Figure 5, the differences were about $-8.7 \%$ to $-16.3 \%$.

\section{Metal drums of non-homogeneous distribution}

For the clearance measurement operation of decommissioning in nuclear research institutes, the judgment of the compliance of the low radioactivity waste with the IAEA clearance standards $(\leq 0.1 \mathrm{~Bq} / \mathrm{g})$ were carried out. Sampling twenty metal drums of non-homogeneous distribution containing aluminum waste were measured for the residualradioactivity. Comparison of measurement difference between two systems is given in Figure 6. The maximum difference in ${ }^{137} \mathrm{Cs}$ was $0.2 \%$ - 39\%. The measurement results of the five of the 20 drums were lower than the MDA value and the measurement values obtained by the HPGe detectors were about 0.002 Bq/g.

\section{Filling ratio of drum matrix}

Test drums with the same density of plastic matrix ofwhole-drum and respective filling ratios of 25\%, 50\%, $75 \%$ and $100 \%$ were prepared. In the above drums, large-area reference area sources were evenly placed inside. The differences of both systems in measurement radioactivities are given in Figure 7. When the matrix filling ratio was higher than $75 \%$, the radioactivity differences of the critical radionuclides of ${ }^{137} \mathrm{Cs}$, ${ }^{54} \mathrm{Mn}$ and ${ }^{60} \mathrm{Co}$ were less than 20\%. When the matrix filling ratios were between $25 \%$ and $50 \%$, there were few radionuclides whose differences were higher than $20 \%$ for critical radionuclides. 


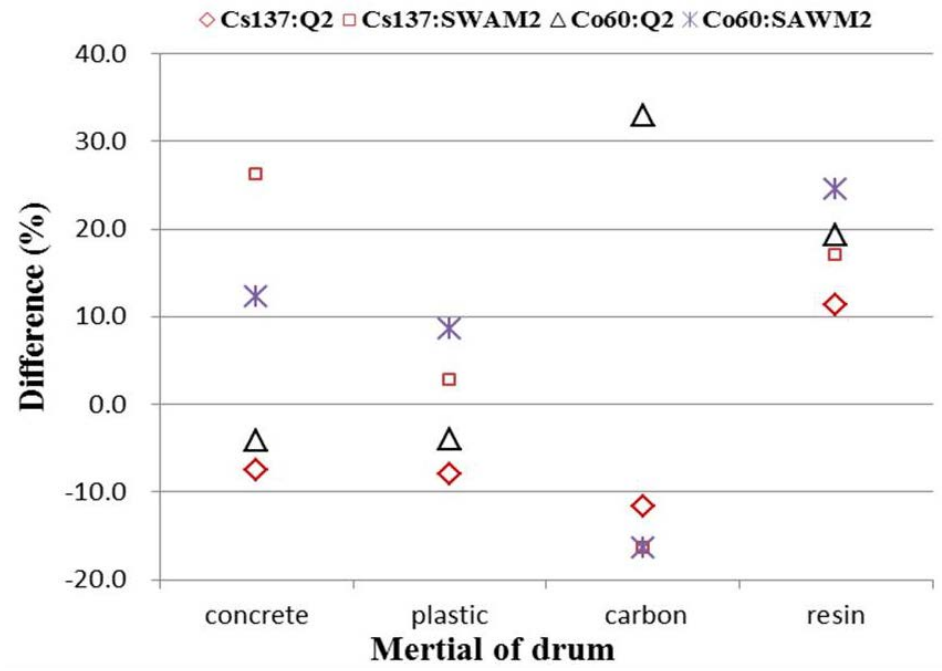

Figure 4. Comparison the measurement of non-metal drums with homogeneous radioactivity distribution.

\section{Cs-137}

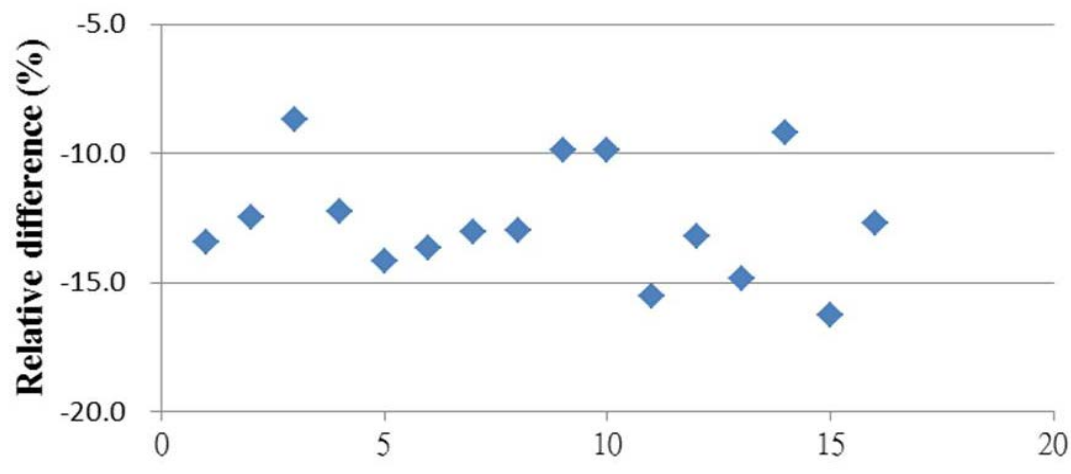

No. of cement drum

Figure 5. Comparison measurement of concrete drums with homogeneous radioactivity distribution.

\section{Cs-137}

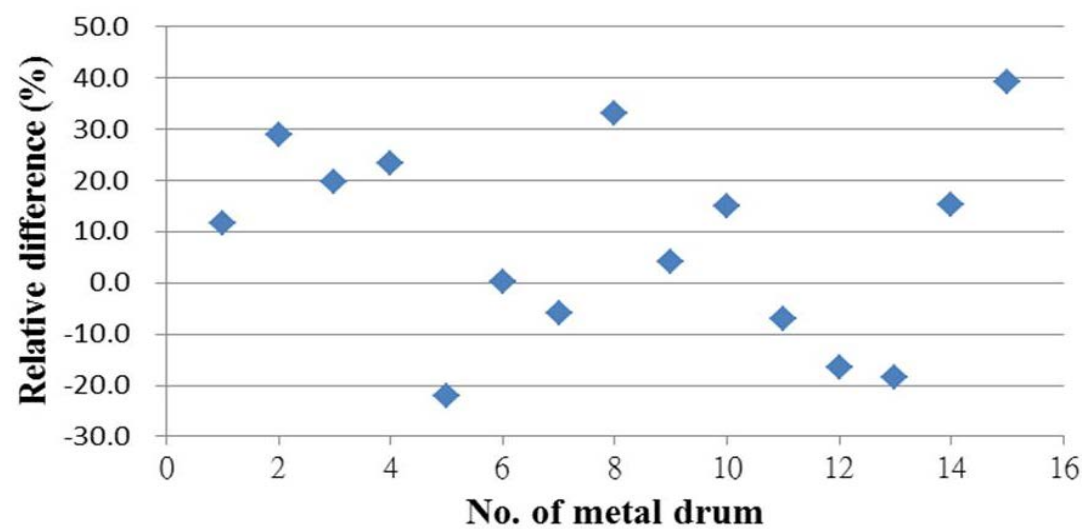

Figure 6. Comparison the measurement of waste metal drums with non-homogeneous radioactivity distribution. 


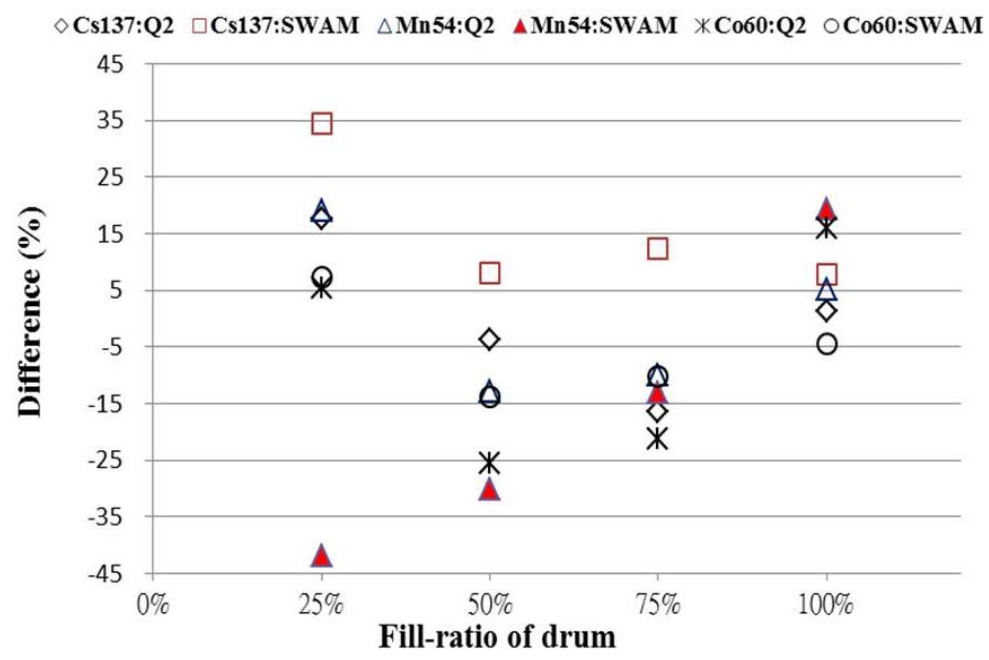

Figure 7. Comparison the difference of radionuclides activity of plastic drums with different filling rate.

\section{Conclusion}

According to the characteristics and the radioactivity measurement results of these two systems, it appeared that the measurement result of scintillation detectors system is suitable for the determination of the long half-life radionuclides for clearance and the release for very low activity wastes. HPGe detectors systemis suitable for establishing historical radiation data of inventory drums in storage sites such as complicated radionuclides and measurements for classification of matrices and low level radioactivity standards. The measurement time consumed by scintillation detectors is much lower than HPGe detectors. However, for the drums which have hotspots and non-homogeneous radioactivity distribution, scintillation detectors have greater measurement differences and MDA than HPGe detectors. In the measurement process of release, it seems obviously that scintillation detectors system is appropriate for a pre-screening process and then verified by HPGe system for sampling.

\section{References}

[1] Yeh, C.H., Yuan, M.C. and Chang, B.J. (2008) Calibration and Characteristics of Gamma-Activity Monitors Used for Decommissioning Waste. 53rd Annual Meeting of the Health Physics Society, Pittsburgh, 13-17 July 2008.

[2] Yuan, M.C., Yeh, C.H., Wang, J.J., Chen, I.J. and Wang, C.F. (2009) The Calibration and Evaluation of a Radioactive Waste Drum Counting System. Appl. Radiat. Isot., 67, 931-934. http://dx.doi.org/10.1016/j.apradiso.2009.01.060

[3] Yuan, M.C., Yeh, C.H., Yeh, C.Y., Chen, I.J. and Wang, C.F. (2009) Proficiency Testing Feasibility Study for the Measurement of Gamma-Emitting Clearance Samples. 17th International Conference on Radionuclide Metrology and its Applications (ICRM 2009), Bratislava, 7-11 September 2009.

[4] Chu, W.H., Yeh, C.H. and Yuan, M.C. (2015) Comparison Exercise on Activity Determination of Radioactive Waste Drums in Taiwan. 20th International Conference on Radionuclide Metrology and its Applications (ICRM 2015), Vienna, 8-11 June 2015. 


\section{Submit or recommend next manuscript to SCIRP and we will provide best service for you:}

Accepting pre-submission inquiries through Email, Facebook, LinkedIn, Twitter, etc.

A wide selection of journals (inclusive of 9 subjects, more than 200 journals)

Providing 24-hour high-quality service

User-friendly online submission system

Fair and swift peer-review system

Efficient typesetting and proofreading procedure

Display of the result of downloads and visits, as well as the number of cited articles

Maximum dissemination of your research work

Submit your manuscript at: http://papersubmission.scirp.org/ 